\title{
Regional Patterns of c-fos mRNA Expression in Rat Hippocampus Following Exploration of a Novel Environment versus Performance of a Well-Learned Discrimination
}

\author{
Ursula S. Hess, ${ }^{1}$ Gary Lynch,, ${ }^{1,2}$ and Christine M. Gall ${ }^{1,3}$ \\ 'Department of Psychobiology, ${ }^{2}$ Center for the Neurobiology of Learning and Memory, and ${ }^{3}$ Department of Anatomy \\ and Neurobiology, University of California at Irvine, Irvine, California 92717
}

Previous studies using c-fos cRNA in situ hybridization demonstrated a differential involvement of hippocampal subfields CA1 and CA3 in the acquisition of an olfactory discrimination (Hess et al., 1995). The present experiments employed the same method to examine changes in neuronal activity associated with two related behaviors: (1) initial exploration of the training apparatus and (2) performance of a well-learned odor discrimination. Rats in the two groups had similar labeling patterns within hippocampus indicating increased expression in all three major subfields with the greatest effect being in CA1. This pattern of "CA1 dominance" was notably different from that produced during early stages of two-odor discrimination learning in prior experiments. Hippocampal labeling in exploration and performance rats differed in that (1) hybrldization was greater in CA1, CA3, and dentate gyrus in the former group and (2) a tendency for labeled cells to occur in clusters was more evident in exploration animals. Levels of c-fos mRNA in olfactory and visual structures were not predictive of expression patterns within hippocampus although labeling in piriform cortex and dentate gyrus was correlated in rats performing a well-practiced discrimination. Moreover, the pattern of hybridization in olfactory bulb was found to be behaviorally dependent. These results, together with those from previous studies, indicate that hippocampus has multiple patterns of regional activation but that one of these is common to very different behavioral circumstances. It is hypothesized that this common pattern emerges whenever the animal responds to distant cues using species-specific or well-learned behaviors and involves coordinated temporal convergence of sensory and septal/brainstem inputs.

[Key words: gene expression, in situ hybridization, odor discrimination learning, olfactory bulb, piriform cortex, visual system]

\footnotetext{
Received May 30, 1995; revised Aug. 7, 1995; accepted Aug. 10, 1995.

We thank Julie Wong for assistance in training animals and Dr. Charles Ribak for helpful discussions. This research was supported by Grant HD24236 and Research Scientist Development Award MH00974 to C.M.G., Grant 00014-89J-1255 from the Office of Naval Research and a Research Scientist Award MH00358 to G.L., and NIMH predoctoral fellowship MH10510 to U.S.H.

Correspondence should be addressed to Dr. Christine M. Gall, Department of Anatomy and Neurobiology, University of California at Irvine, Irvine, CA 92717.

Copyright (C) 1995 Society for Neuroscience $0270-6474 / 95 / 157796-14 \$ 05.00 / 0$
}

The discovery that depolarization and associated calcium influx can stimulate the expression of the immediate-early gene c-fos (Greenberg et al., 1986; Morgan and Curran, 1986) has provided a technique for assessing levels of neuronal activity in brain subdivisions during various behaviors (Morgan et al., 1987; Sagar et al., 1988; Dragunow and Faull, 1989). Experiments using in situ hybridization and immunohistochemical techniques have shown that levels of c-fos mRNA and protein are dramatically changed in sensory/motor systems of animals exposed to appropriate environmental stimuli with the spatial location of the affected neurons varying according to cue composition (Hunt et al., 1987; Sharp et al., 1989; Ehret and Fischer, 1991; Guthrie et al., 1993). Regionally differentiated patterns of $\mathrm{c}-$ fos induction have also been observed in studies using shock avoidance training (Nikolaev et al., 1992) and conditioning vs pseudo-conditioning of the nictitating membrane reflex (Irwin et al., 1992).

The present work used c-fos expression to investigate the possibility that the subdivisions of hippocampus become differentially active across behavioral circumstances. Neuroanatomical investigations have established that the two pyramidal cell fields of hippocampus (i.e., CA1 and CA3) project to very different target regions (Swanson and Cowan, 1977; Witter et al., 1989; Van Groen and Wyss, 1990; Jay and Witter, 1991). Accordingly, variations in the balance of activity between the two regions could result in variations in hippocampal contributions to behavior. This idea stands in contrast to hypotheses positing a unitary function for the hippocampal formation. Previous work in this laboratory has demonstrated that $\mathrm{c}-$ fos mRNA expression is elevaled in an equivalent and correlated fashion in the hippocampal regions CA 3 and $\mathrm{CA} 1$ of rats engaged in "nose poking" behavior for rewards in an open field. In contrast, field CA3 exhibited a much larger increase than CA1 when animals were switched to a paradigm which required them to discriminate between two odors before making a nose poke response. Interestingly, induction of c-fos mRNA in the dentate gyrus was not observed in either training condition. Thus, the hippocampus did not respond as a unit to changes in task demands and behavior but instead exhibited regionally differentiated increases and decreases in c-fos mRNA expression.

The experiments reported here sought to determine if other behavioral circumstances alter the balance of activity in hippocampus in a manner different from those just described. Two conditions quite different from each other but nonetheless related to the nose-poke/olfactory discrimination paradigms were used: (1) initial exploration of the olfactory training apparatus and (2) discrimination performance involving already learned odors. 
These two behaviors constitute the beginning and end points of a sequence in which the behaviors studied in the earlier experiment (i.e., nose-poke/respond to odors) are intermediary steps. Levels of c-fos expression were also assessed in olfactory and visual structures as measures of the selectivity of any changes occurring in hippocampus, as well as to identify sensory effects that might relate to shifts in hippocampal activity patterns.

\section{Materials and Methods}

\section{Animals}

Male Wistar rats from Hilltop Laboratories (26-38 d old at sacrifice) were used. They were housed in groups of four to six in transparent Plexiglas cages $(12$ " $\times 22$ ") on a regular $12 \mathrm{hr}$ day-night cycle. In order to decrease cage odor, animals were placed on a fat sufficient test diet (Harlan-Teklad) given ad libitum. Rats were water deprived and only allowed to drink from a glass bowl placed in the home cage for 8 min per day. Animals were handled for $\sim 2$ min per day following behavioral training sessions to familiarize them with the experimenter.

\section{Training apparatus}

The odor discrimination training apparatus is an open wedge-shaped chamber with six separate "odor alleys" and an extension at its thin end that serves as a starting compartment (see Hess et al., 1995, for a detailed description). Two holes were placed at the end of each of the odor alleys. One of these holes contained a protruding glass connector and served as an outlet for the odor-carrying tubes. The other, placed directly above the first, was larger and served as a target for nose poke responses. A $1 \mathrm{ml}$ syringe was used to administer $0.025 \mathrm{ml}$ water reward through these larger holes for every correct response. A strobe light was mounted $8 \mathrm{~cm}$ above the test apparatus and flashed for $2 \mathrm{sec}$ following incorrect responses. Odor discrimination training was conducted in a dimmed room.

Odors were generated by forcing 7 liters per minute of air through $125 \mathrm{ml}$ flasks containing pure peppermint extract (Schilling; Hunt Valley, MD) or amyl acetate (Fisher; Tustin, CA). A 1:12 dilution of saturated odor vapor in air was used for both odors. These dilutions were chosen to match perceived odor intensities. The outlet of each flask was connected to Tygon tubing $(0.5 \mathrm{~cm}$ inner diameter) that carried the odorized air and ejected it into the training apparatus through a given odor outlet during trials. Odor release was interrupted between trials through the use of an exhaust valve that was placed in the line ahead of the odor flasks and diverted the air flow.

\section{Odor discrimination training procedure}

Odor training was preceded by two sessions ( $50 \mathrm{~min}$ total in $2 \mathrm{~d}$ ) during which rats learned to nose poke for water reward in the training apparatus. During these sessions, every nose poke at one of the six holes was rewarded with water, as long as consecutive pokes were not at the same hole. This served to familiarize the animals with the training apparatus and the nose poke response that would be required of them during odor discrimination. Subsequently, over the course of several days, rats were trained on the two-odor discrimination. They learned to nose poke at the positive odor (peppermint), which was reinforced with water, and avoid the negative odor (amyl acetate), poking at which resulted in a mildly aversive 2 sec strobe flash. For each trial, the odors were randomly assigned to two of the six arms. The odors were turned off $2 \mathrm{sec}$ after the nose poke. Nose pokes into unassigned holes had no consequence. However, if no correct or incorrect response occurred within $1 \mathrm{~min}$, the trial was terminated, the odors turned off, and the animal returned to the start chamber.

\section{Animal treatment groups}

Home cage controls ("naive"). In order to determine baseline levels of c-fos mRNA expression, eight rats were killed without undergoing any type of experimental manipulation. They were taken from the home cage, anesthetized, and intracardially perfused with paraformaldehyde, as described below. Cage-controls were not water deprived or handled. Five of these animals were $26-34 \mathrm{~d}$ old at sacrifice and served as controls for the exploration group. Three of the rats were $35-38 \mathrm{~d}$ old at sacrifice and served as controls for the familiar two-odor discrimination group. These two groups were combined for quantitative analyses.

Exploration of a novel environment. Seven animals (31-34 d old at sacrifice) were water deprived and handled ( $5 \mathrm{~min} / \mathrm{d}$ ) for 7-10 d. On the day following the last period of handling, the rats were placed in the odor discrimination training apparatus for $30 \mathrm{~min}$ and then sacrificed. This environment was novel to the animals and they all actively explored the apparatus for at least part of the $30 \mathrm{~min}$ period.

Performance of a familiar two-odor discrimination ("overtrained"). Five rats (35-38 d old at sacrifice) were trained to criterion ( $\geq 80 \%$ correct in a block of 10 trials, and active avoidance of the "negative" odor) on the odor discrimination problem. This took an average ( \pm SD) of $200 \pm 53 \mathrm{~min}$, and $171 \pm 54$ trials spread across $3-6(4.6 \pm 1.1)$ d. Following initial learning of the problem, training was continued for $145 \pm 39 \mathrm{~min}, 274 \pm 38$ trials, spread across $4-5(4.2 \pm 0.4) \mathrm{d}$, during which time rats maintained their level of performance. The reason for the variability in training sessions was due to different rates of learning by the animals. In any case, all rats were "overtrained" on the problem as evidenced by their rapid and accurate performance in later sessions. On the last day, animals received $66 \pm 5$ trials in $30 \mathrm{~min}$, after which time they were sacrificed. This time point was chosen because c-fos mRNA levels have been shown to peak at about $30 \mathrm{~min}$ following stimulation in a variety of paradigms (Shin et al., 1990; reviewed by Morgan and Curran, 1991). Virtually no errors were made in the last session.

Data from two groups described in a previous study (Hess et al., 1995) were included in some of the analyses described below for purpose of comparison. The animals in these groups were at intermediate stages of the olfactory discrimination paradigm beginning with "exploration" and ending with "overtraining"; that is, (1) a nose-poke group performing a well-practiced nose-poke response for water reward without odor stimulation, and (2) a group of rats previously trained to nosepoke, but sacrificed in the early stages of learning the two-odor discrimination (see Discussion).

\section{In situ hybridization}

Levels of c-fos mRNA were examined in tissue sections using in situ hybridization of a ${ }^{35} \mathrm{~S}$-labeled cRNA probe complementary to rat c-fos mRNA [i.e., to positions 583-1250 of clone pc-fos (rat)- 1 by Curran et al. (1987)]. The antisense cRNA was transcribed from Pst I-linearized recombinant clone $\mathrm{pBS} / \mathrm{rfos}$ with $\mathrm{T} 7 \mathrm{RNA}$ polymerase in the presence of uridine $5^{\prime}-\left[\alpha-{ }^{35} \mathrm{~S}\right]$ thio]triphosphate. The sense RNA sequence was generated from the same template using T3 RNA polymerase after linearization with $E c o$ RI.

Brain tissue was processed for in situ hybridization as previously described (Gall et al., 1991; Lauterborn et al., 1993). Briefly, animals were overdosed with sodium pentobarbital and intracardially perfused with $4 \%$ paraformaldehyde in $0.1 \mathrm{M}$ phosphate buffer $(\mathrm{pH} \mathrm{7.2)}$. Brains were postfixed, cryoprotected, and coronal tissue sections ( $30 \mu \mathrm{m}$ thick) cut on a freezing microtome. Tissue was pretreated with proteinase $\mathrm{K}$ ( $1 \mu \mathrm{g} / \mathrm{ml}$ in $0.1 \mathrm{M}$ Tris buffer, $\mathrm{pH} 8.0$, with $50 \mathrm{mM}$ EDTA) for $30 \mathrm{~min}$ at $37^{\circ} \mathrm{C}$ followed by $0.25 \%$ acetic anhydride in $0.1 \mathrm{M}$ triethanolamine for $10 \mathrm{~min}$. Hybridization was conducted at $60^{\circ} \mathrm{C}$ for $38-40 \mathrm{hr}$ with the ${ }^{35} \mathrm{~S}$-cRNA at $1 \times 10^{6} \mathrm{cpm} / 100 \mu \mathrm{l}$. Following this incubation, sections were rinsed in $4 \times \mathrm{SSC}$ (saline sodium citrate buffer; $1 \times \mathrm{SSC}=0.15$ $\mathrm{M} \mathrm{NaCl}$ and $0.015 \mathrm{~m} \mathrm{Na}$ citrate, $\mathrm{pH} 7.0$ ), treated with $20 \mu \mathrm{g} / \mathrm{ml} \mathrm{ribo-}$ nuclease $\mathrm{A}\left(35 \mathrm{~min}, 45^{\circ} \mathrm{C}\right)$, and washed through descending concentrations of SSC to a final stringency of $0.1 \times \mathrm{SSC}$ at $60^{\circ} \mathrm{C}$. Sections were mounted and air dried on gelatin coated slides, and the distribution of hybridization was evaluated using Amersham $\beta$-max Hyperfilm and Kodak NTB2 emulsion autoradiography with exposure intervals of 1-2 d and $2-3$ weeks, respectively. No cellular labeling was seen in tissue hybridized to the sense cRNA sequence.

\section{Autoradiographic unalysis}

Densitometric analysis of film autoradiograms was carried out using the Intel based MCID image analysis system (Imaging Research, St. Catherine's, Ontario, Canada). Autoradiographic film optical densities were linearized and calibrated relative to densities obtained from ${ }^{14} \mathrm{C}$-labeled brain paste standards exposed to each sheet of film. This allowed the conversion of optical density readings to $\mathrm{cpm} / 25 \mu \mathrm{g}$ protein (see Gall et al., 1994 for details). For all brain areas analyzed, multiple measures were collected from at least four to five tissue sections at different rostro-caudal levels. Individual section means were averaged to yield a mean and standard deviation for the individual animal. Regional in situ hybridization densities were quantified for: (1) intermediate levels of the main olfactory bulb, granule cell layer and periglomerular aspects 

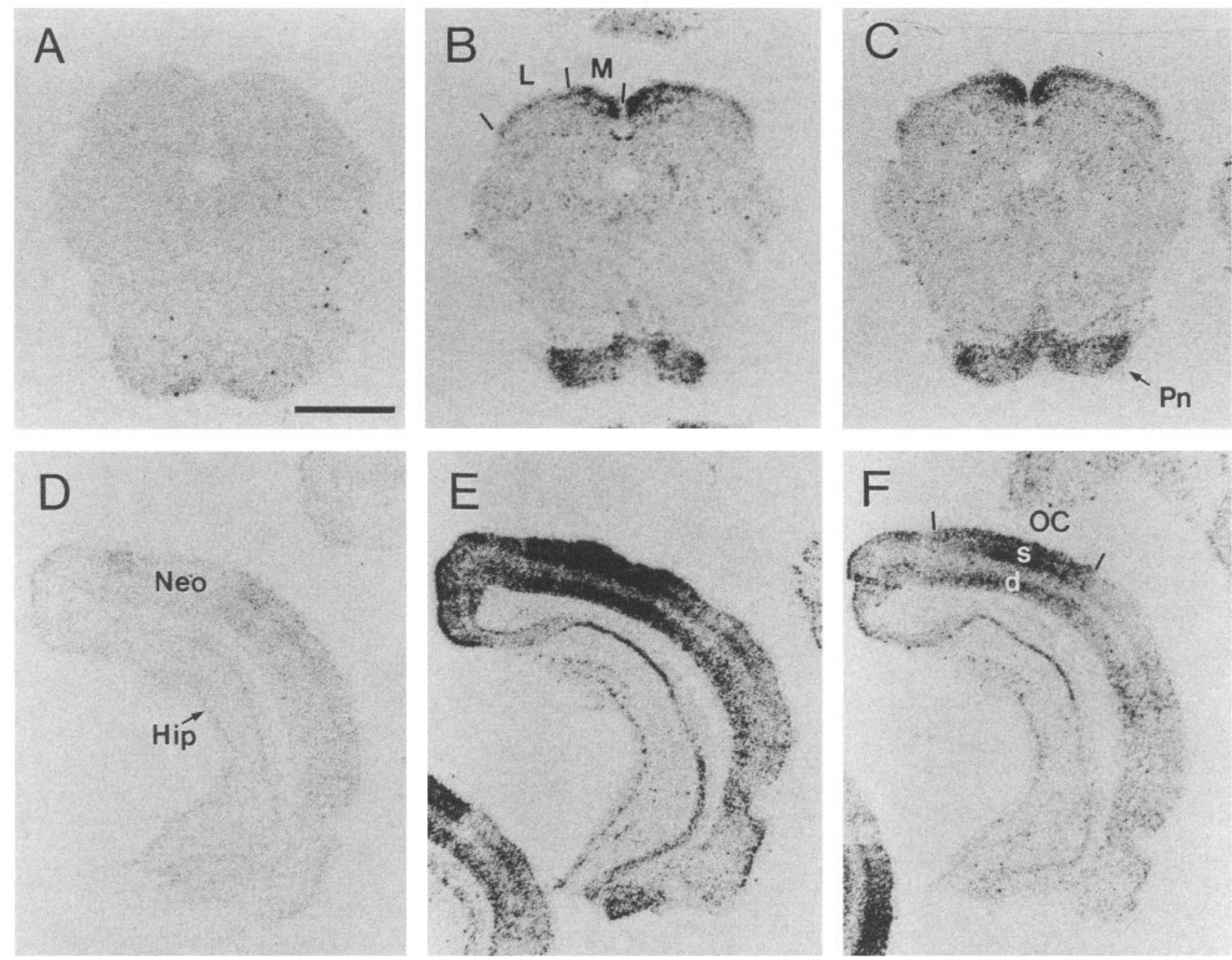

Figure 1. c-fos mRNA expression in the visual system. Bright-field photomicrographs of film autoradiograms showing levels of c-fos cRNA hybridization in sections through the superior colliculus $(A-C)$ [medial $(M)$ and lateral $(L)$ sectors are bracketed] and the occipital cortex $(O C)(D-$ $F$ ) for the three groups of animals. Basal levels of expression were generally low in cage-controls $(A, D)$, but greater in neocortical $(N e o)$ than in brainstem regions. Labeling was dramatically increased above these control levels in the exploration group $(B, E)$ in most regions, particularly in the medial superior colliculus $(M)$ and superficial $(s)$ and deep $(d)$ layers of occipital cortex. Also note dense hybridization in the pontine nuclei $(P n)$ and hippocampus (Hip) of these rats. Overtrained animals $(C, F)$ showed intermediate levels of hybridization in occipital cortex, and denser labeling in medial superior colliculus than exploration rats. Scale bar, $2 \mathrm{~mm}$.

of the glomerular layer [where focal points of c-fos mRNA expression have been noted following extended peppermint or amyl acetate odor exposure] (Guthrie et al., 1993; Hess and Gall, unpublished observations); (2) medial and lateral aspects of the superficial gray layer of superior colliculus; (3) layer II of rostral piriform cortex (through the rostro-caudal levels of septum); (4) superficial (layers II/ III) and deep (layers V/ VI) rostral occipital cortical areas 2MM, 2ML, and $2 \mathrm{~L}$ as defined by Paxinos and Watson (1986), which lie dorsal to the hippocampus and lateral to retrosplenial cortex; and (5) dorsal hippocampus: stratum pyramidale (fields $\mathrm{CA} 1 \mathrm{~b}$ and $\mathrm{CA} 3$ ) and the suprapyramidal blade of stratum granulosum. Since the exact boundaries of field CA1 are difficult to distinguish on film autoradiograms, only the central portion, overlying the dorsal blade of the dentate gyrus, was measured. As described in the Results, regional c-fos mRNA expression ratios were sometimes calculated in order to determine the relative balance of labeling densities between areas within the same animal. This sort of analysis also served as an "internal control," in that it helped reduce inter-animal variability for purpose of comparison. One-way analyses of variance (ANOVA), two-tailed $t$ tests, and regression analyses were used for statistical comparisons. The Student-Newmann-Keuls test was used for post-hoc comparisons. A 95\% confidence level $(p \leq 0.05)$ had to be reached for differences to be considered significant.

\section{Results}

\section{Visual system}

Figure 1 shows regions of the visual system selected for quantitative analysis and illustrates representative cases from each of the three groups. In both "exploration" and "overtrained" rats, the expression of c-fos mRNA was increased above "naive cage control" levels in superior colliculus and occipital cortex. Densitometric measures of these fields are presented in Figure 2. As shown, c-fos mRNA levels in control rats were low but slightly greater in the occipital cortex than in superior colliculus. There were no reliable differences between medial versus lateral colliculus; however, values for the superficial versus deep layers of cortex were highly correlated $(r=0.99)$ across rats with the former region having slightly more labeling ( $p=0.02$, paired $t$ test). In the exploration group (Fig. $1 B, E$ ), hybridization was greatly elevated above control levels in all four regions sampled ( $p<0.0001$ ANOVA, $p<0.001$ Student-Newmann-Keuls) with the cortex showing a greater increase than the colliculus 


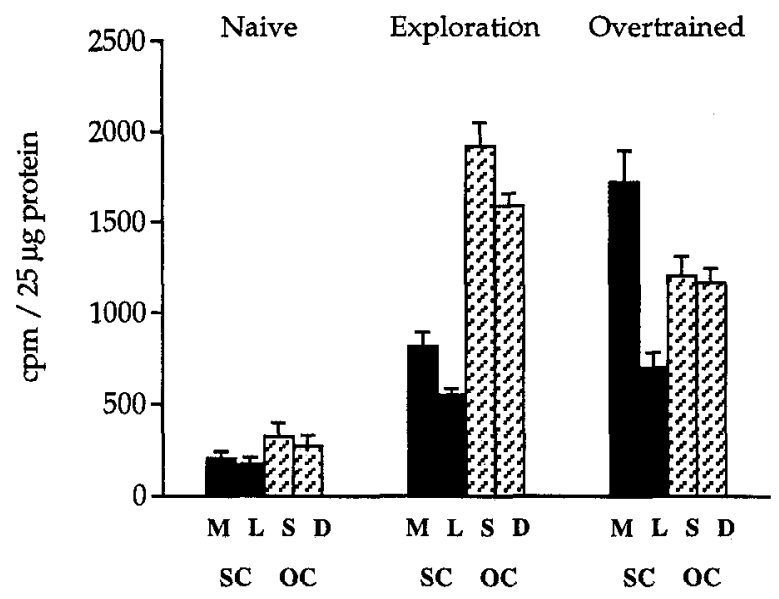

Figure 2. Bar graph summarizing densities of hybridization to c-fos mRNA in superior colliculus and visual cortex in the three groups of animals. Regions measured include: medial $(M)$ and lateral $(L)$ aspects of superficial superior colliculus $(S C)$, and superficial $(S)$ and deep $(D)$ layers of occipital cortex $(O C)$ (see Fig. 1 for fields measured). Bars indicate group mean values ( $\pm \mathrm{SE}$ ). Expression of $\mathrm{c}$-fos $\mathrm{mRNA}$ was low in naive rats but markedly increased, with regional differentiation, in both the exploration and overtrained groups. Exploration rats had significantly more hybridization in superficial and deep visual cortex than overtrained rats $(p<0.0001$ ANOVA; $p<0.001$ and $p<0.01$, respectively, Student-Newmann-Keuls), while overtrained rats had greater labeling in medial, but not lateral superior colliculus $(p<0.0001 \mathrm{ANO}-$ VA, $p<0.001$ Student-Newmann-Keuls). The relative difference between labeling of medial and lateral superior colliculus was greater for overtrained than for exploration rats $(p=0.0019$ ANOVA, $p<0.01$ Student-Newmann-Keuls).

(Fig. 2). For these rats, labeling was greater in the medial than in the lateral superior colliculus ( $p<0.01$, unpaired $t$ test) and greater in superficial than deep cortex $(p=0.001$, paired $t$ test); however, the laminar ratio was not significantly different from controls.

Hybridization to c-fos mRNA in visual regions was also greatly elevated above control levels in rats performing a familiar odor discrimination, but the pattern of this increase was different than that for "exploration" rats. First, the magnitude of the increase was significantly lower for visual cortex but larger for superior colliculus (Fig. 2). As a result, the pronounced regional difference in expression found in the exploration group was not present in the odor discrimination group. Second, within structure distributions were not the same: the discrepancy between medial versus lateral colliculus $(150 \pm 41 \%)$ was significantly greater for the overtrained rats while the discrepancy between superficial versus deep cortex was smaller and not statistically significant (Fig, 2). Thus, exploration had a greater effect on visual cortex than did responding to familiar odors while the reverse was true for the superior colliculus.

\section{Olfactory system}

Olfactory structures were among those regions exhibiting the highest levels of expression in cage-control rats. Levels of c-fos mRNA in olfactory bulb and cortcx relative to other telencephalic structures are shown in the pseudocolor images of film autoradiograms in Figure 3. Figure 4 summarizes the quantitative results for the three groups. In the olfactory bulb of control rats, granule and glomerular layer expression were highly correlated $(r=0.98)$ and not detectably different. As seen in both Figures 3 and 4 there was a large increase in hybridization in both granule cell and glomerular layers in tissue from the exploration and overtrained groups. For the exploration group, this was accompanied by a pronounced change in the balance of expression between the glomerular versus granule cells; that is, in contrast to the control group, expression was much greater in the granule cell layer than in the glomerular layer $(56 \pm 16 \%$; $p<0.0001$ ANOVA, $p<0.001$ Student-Newmann-Keuls; Fig. $4 A$ ). There was also a change in relative labeling density between medial and lateral aspects of the bulb. While there was no reliable side-to-side difference in the glomerular layer in cage-controls, exploration rats had significantly greater hybridization medially than laterally (Fig. $4 B$ ). Control rats did have more labeling in the medial, as compared to the lateral, sector of the granule cell layer but this bias was more pronounced in the exploration group.

Expression of c-fos mRNA was clearly increased above control levels in the olfactory bulbs of rats performing a familiar odor discrimination but, as was the case for visual structures, there were differences from the results ohtained for the exploration group. First, the variation in labeling between glomerular layer and granule cell layer for overtrained rats was less pronounced $(p<0.0001$ ANOVA, $p<0.01$ Student-NewmannKeuls; Fig. 4A). Second, differences in the labeling of medial versus lateral aspects of the bulb were not significant. The latter point is illustrated in graphs of Figure $4, B$ and $C$, which plot within-subject ratios of labeling densities in medial versus lateral olfactory bulb for the three groups. Finally, while expression in the medial and lateral segments of the glomerular layer was highly correlated in the control and exploration rats $(r>0.87)$, this was not the case for the overtrained animals $(r=0.21)$.

These data demonstrate that exploration produces a bulb response that is differentiated between layers (granule $>$ glomerular) and within layers (medial $>$ lateral). Performance of a discrimination involving familiar odors also increases expression but in a more homogeneous fashion.

In piriform cortex, c-fos cRNA hybridization was about fivefold greater in the exploration group than in cage-controls (Fig. 5). Overtrained odor discrimination rats had intermediate c-fos mRNA levels in the piriform at about two-fold control values. The exploration and overtrained group values were significantly different from one another $(p<0.0001$ ANOVA, $p<0.001$, Student-Newmann-Keuls). Interestingly, hybridization was greater in the olfactory cortex than in the glomerular and granule cell layers of the olfactory bulb in the exploration group, while the reverse was true in overtrained rats (compare Figs. 4 and 5; see Fig. 3). Thus, in both absolute and relative terms, performance involving familiar odors by experienced animals had only modest effects on piriform cortex.

\section{Hippocampus}

As can be seen in the pseudocolor images of film autoradiograms presented in Figure 3, hybridization within hippocampus was uniformly low in controls (Fig. 3C) and markedly greater in exploration (Fig. $3 F$ ) and odor discrimination (Fig. $3 I$ ) rats. In the latter groups, the largest increase above control appeared to occur in ficld CAl (asterisks, Fig. 3F,I). The quantitative measures of hybridization densities presented in Figure 6 agree with these observations. There were no statistical differences between labeling in the three principal hippocampal subfields in the control group but regional mRNA levels were correlated in within rat comparisons (CA1 vs CA3, $r=0.89$; CA3 vs stratum granulosum, $r=0.86$ ). In the exploration group, c-fos mRNA 

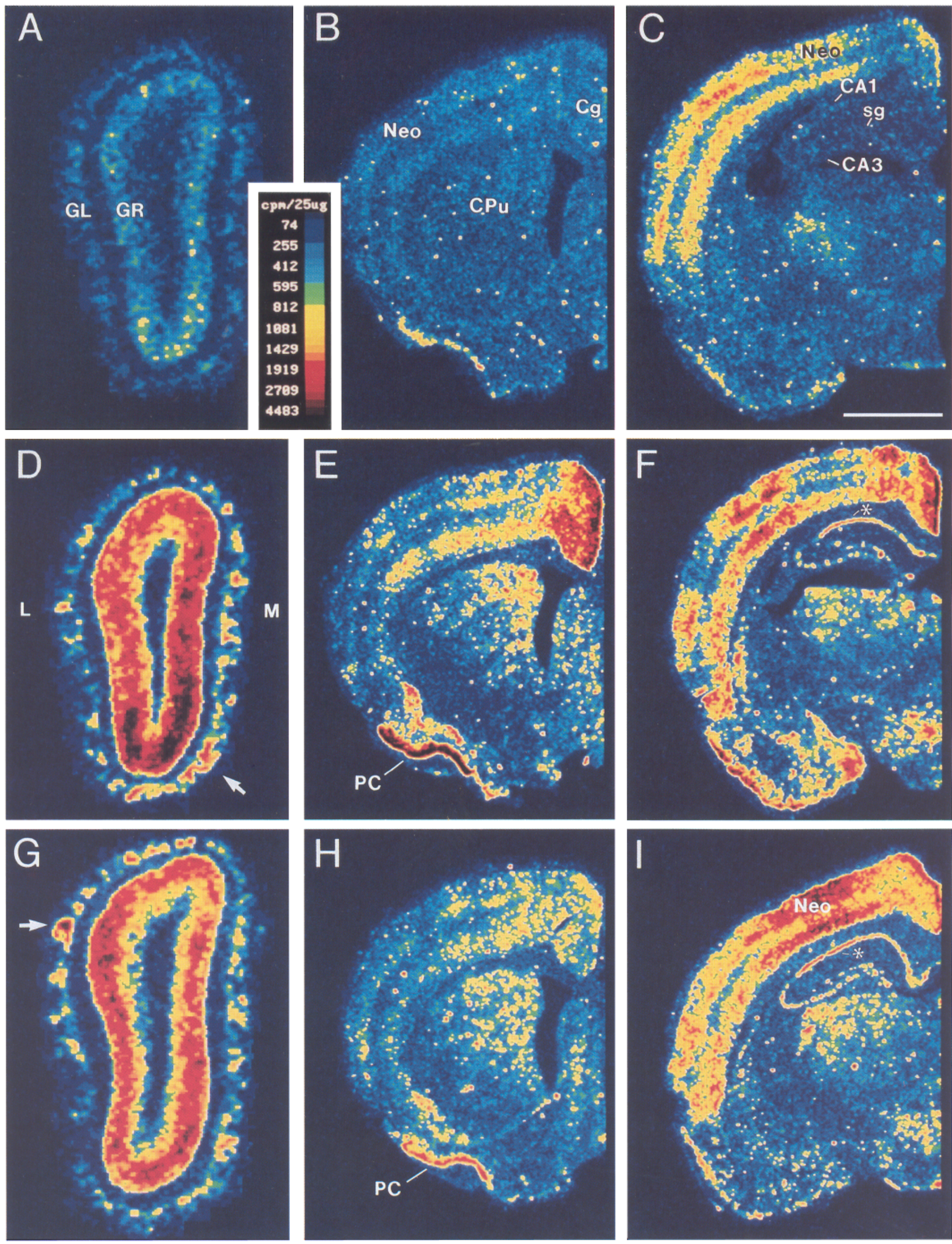
levels were significantly greater than in control rats for all three subdivisions with the greatest elevation being in field CA1; hybridization was $74 \pm 37 \%$ (mean $\pm \mathrm{SD}$ ) greater in field CA1 than in CA3 (Fig. 6B), and $94 \pm 25 \%$ greater than in stratum granulosum ( $p<0.0001$ ANOVA, $p<0.001$ Student-Newmann-Keuls). Hybridization in CA3 and stratum granulosum did not differ significantly. Thus, exploration not only increased c-fos expression but led to a marked change in the balance of c-fos mRNA between the three subdivisions. Additionally, the correlations between hippocampal subdivisions observed in the control group were absent in animals exploring the new environment (CA1 vs $\mathrm{CA} 3, r=0.32 ; \mathrm{CA} 3$ vs stratum granulosum, $r=0.32$ )

Animals performing a well-learned odor discrimination had a similar hippocampal c-fos expression profilc as rats exploring a novel environment. All three subdivisions demonstrated a significant increase in expression above control levels (Fig. 6A). Levels of hybridization in the exploration group were significantly greater than in the overtrained group in field CAl, stratum granulosum, and field CA3 $(p<0.0001$ ANOVA; $p<0.001$ for CA1 and stratum granulosum, $p<0.05$ for CA3 StudentNewmann-Keuls). As in the novel envirunnent group, overtraining led to a change in the balance of expression between the subdivisions. As shown in Figure $6 B$, hybridization in region CA1 was $53 \pm 24 \%$ greater than in $\mathrm{CA} 3$ and $99 \pm 14 \%$ greater than in stratum granulosum $(p=0.0001$ repeated measures ANOVA, $p<0.001$ Student-Newmann-Keuls). However, in contrast to the exploration group, expression was significantly greater in CA3 than in stratum granulosum ( $p=0.0001$ repeated measures ANOVA, $p<0.05$ Student-Newmann-Keuls) and labeling in the three subdivisions was highly correlated (CAl vs CA3, $r=0.84$; CA3 vs stratum granulosum, $r=0.86$ ).

Comparison of the results for hippocampus with those for other brain regions revealed further and interesting differences between the control, exploration, and overtrained groups. The values for all three hippocampal subdivisions were correlated with those for visual and piriform cortices in the home cage controls $(r>0.87)$, but not in the exploration group $(r \leq 0.4$ for five of six comparisons). In overtrained rats, c-fos expression in the three hippocampal subfields remained highly correlated with that in piriform cortex $(r>0.85)$, but much less so with that in visual cortex $(r=0.44-0.76)$.

Figure 7 presents high magnification bright-field photomicrographs showing the cellular localization of hybridization in the three hippocampal subdivisions (stratum granulosum and stratum pyramidale fields CA3 and CA1) as observed in the three groups. Included for comparison are two treatment groups that were described in an earlier paper (Hess et al., 1995): (1) animals performing a well-learned nose-poke response for water reward in the absence of olfactory cues, and (2) rats in the early stage of learning the two-odor discrimination in a familiar apparatus (see Discussion). Expression of c-fos mRNA in the dentate gyrus of exploration (Fig. 7D) and overtrained (Fig. 7M) rats appeared patchy with pairs or small groups of well-labeled granule cells separated some distance from one another by unlabeled cells. The granule cells were particularly heavily labeled in animals exploring a novel environment (Fig. $7 D$ ). Labeling of the granule cells appeared comparable to that in control rats for the remaining two behavioral groups (Fig. $7 G, J$ ). Cells in field CA3 were not intensely labeled but clusters of neurons with higher grain densities were evident; there were no apparent differences between the four experimental groups, although exploration rats had statistically significantly more labeling than overtrained rats. Hybridization in field CA1 varied considerably across the four experimental groups being greatest in the exploration (Fig. $7 F$ ) and overtrained (Fig. $7 O$ ) animals, at intermediate levels in rats that performed a practiced nose-poke response (Fig. 7I), and only slightly above background in animals that had recently acquired a two-odor discrimination (Fig. $7 L$ ). The exploration group again had clusters of intensely labeled pyramidal cells (Fig. $7 F$ ), while hybridization in the rats responding to well-learned odors was more diffuse (Fig. 7O).

\section{Discussion}

Previous work in this laboratory showed that changes in behavior are associated with subfield-specific changes in c-fos expression within hippocampus (Hcss ct al., 1995). The present experiments demonstrate the converse and somewhat surprising result, that is, that quite different behaviors are accompanied by similar relative levels or patterns of expression in this structure. These points are illustrated by Table 1 which summarizes the relative levels of c-fos $\mathrm{mRNA}$ across hippocampal subdivisions in four of several stages in the sequence leading to rapid acquisition of novel odor discriminations. Photomicrographs showing the intrahippocampal distribution of c-fos expression in representative cases for these four experimental groups, and the home cage control group, are included in Figure 8.

One can see that exploration of a novel environment (the olfactory training apparatus) and performance of a well-learned odor discrimination elicit a common pattern of c-fos expression / neuronal activation in the hippocampus (CAl $>\mathrm{CA} 3 \geq \mathrm{SG}$ ) (Fig. $8 A, D$ ). Since these two behaviors are in many respects

\section{$\leftarrow$}

Figure 3. c-fos mRNA expression in the olfactory system and hippocampus. Calibrated pseudocolor images of film autoradiograms showing densities of hybridization at the level of the main olfactory bulb $(A, D, G)$, rostral piriform cortex $(B, E, H)$, and rostral hippocampus $(C, F, I)$ for individual rats from each of three groups. In naive rats $(A-C)$, c-fos mRNA levels were generally low, with greater expression in the piriform cortex and portions of neocortex. In the exploration group $(D-F)$, hybridization densities were dramatically increased above control levels. Particularly dense labeling was observed in olfactory bulb, piriform cortex $(P C)$, cingulate cortex $(C g)$, and portions of neocortex $(N e o)$. Note that $\mathrm{c}-f o s$ expression was significantly greater in medial $(M)$ versus lateral $(L)$ regions of the granule $(G R)$ and glomerular layers $(G L)$ of olfactory bulb $(D$; particularly dense labeling was observed in the ventro-medial sector, arrow). In hippocampus of exploration rats, pyramidal cells in subfield CA1 $(F$; see asterisk) were more densely labeled than those in field CA3 or the granule cells of the dentate gyrus $(\mathrm{sg}$ ). Animals overtrained on the twoodor discrimination $(G-I)$ also showed c-fos mRNA levels that were significantly greater than control, but the regional distribution of labeling was different from that found in the exploration group. Portions of neocortex, piriform cortex, and the olfactory bulb showed particularly dense hybridization, but there was no significant difference in labeling in the granule cell layer between medial versus lateral bulb and there was a trend uppusite to that obtained in the exploration group with regard to the glomerular layer (note dorso-lateral focus of activation, arrow). There was substantially less labeling in the piriform cortex compared to that seen in the exploration group while cingulate cortex had intermediate levels of expression. The regional pattern of hybridization in hippocampus of overtrained animals was similar to that in the exploration group, with CA1 pyramidal cells ( $I$, asterisk) having greater levels of labeling than CA3 neurons or the granule cells. The values on the color calibration bar are in cpm/25 $\mu \mathrm{g}$ protein. Scale bars: $B-C, E-F, H-I, 2162 \mu \mathrm{m} ; A, D, G, 1039 \mu \mathrm{m}$. Abbreviation: $C P u$, caudate-putamen. 


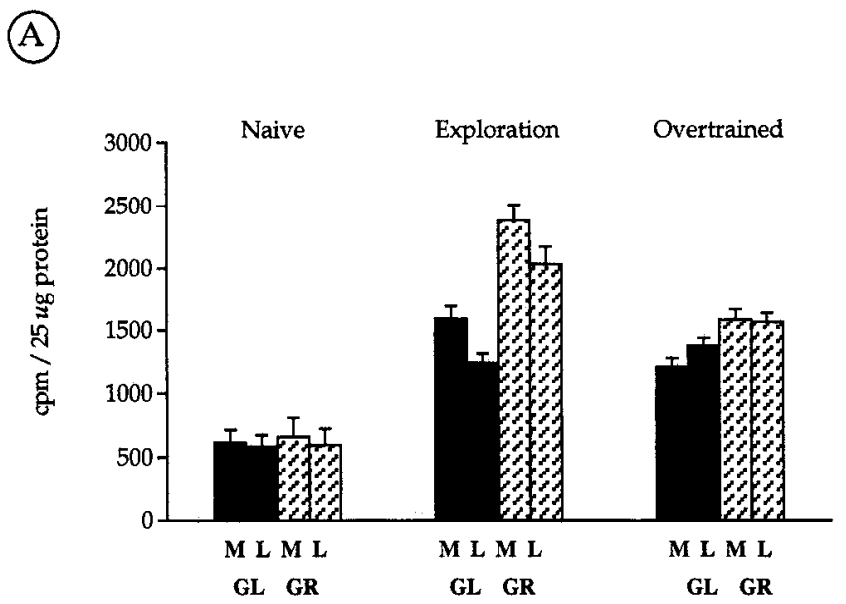

(B)
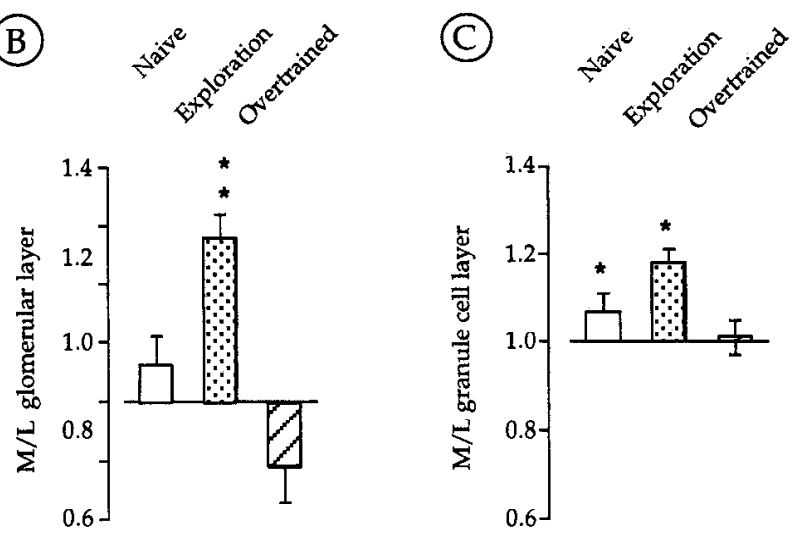

Figure 4. Bar graphs illustrating $(A)$ mean levels of c-fos cRNA hybridization in the main olfactory bulb for each of the three groups, and $(B, C)$ medial to lateral field ratios for the granule and glomerular layers. Regions measured include the medial $(M)$ and lateral $(L)$ glomerular layer $(G L)$ and the medial and lateral granule cell layer $(G R)$. $A$, In the olfactory bulb of "naive" rats, granule and glomerular layer labeling were both low and not detectably different. Exploration and overtrained rats had significantly increased levels of hybridization in medial and lateral portions of both laminae $(p<0.0001$ ANOVA, $p<0.001$ Student-Newmann-Keuls) but differed in the laminar distribution of labeling. $B$ and $C$, Medial versus lateral field labeling ratios demonstrate a significant medial bias for the glomerular layer $(B)$ and granule cell layer $(C)$ of the exploration group and a smaller medial bias for the control group, but no reliable differences between sides in the overtrained group. The trend toward greater labeling in the lateral versus the medial sector of the glomerular layer in the overtrained animals $(B)$ did not reach statistical significance $\left({ }^{*}, p \leq 0.0005 ;{ }^{*}, p<0.04\right.$; paired $t$ tests).

disparate, this may represent a "common mode" of hippocampal functioning, that is, one which emerges during a wide variety of circumstances and that makes a generalized contribution to behavior. Two features are noteworthy about the pattern. First, it includes modest induction in the granule cells of the dentate gyrus, a structure that had proven to be singularly unresponsive in prior experiments. Second, it is associated with a response in field CAl that is decidedly greater than that of the other two subdivisions. It is possible that these events are related. Field CA1, particularly in the rostral regions evaluated in the present experiments, receives the great majority of its afferents from the CA3 pyramidal neurons (reviewed by Amaral and Witter, 1989). Thus, a modest change in aggregate activity or, perhaps more importantly, in the degree of moment to moment synchrony of
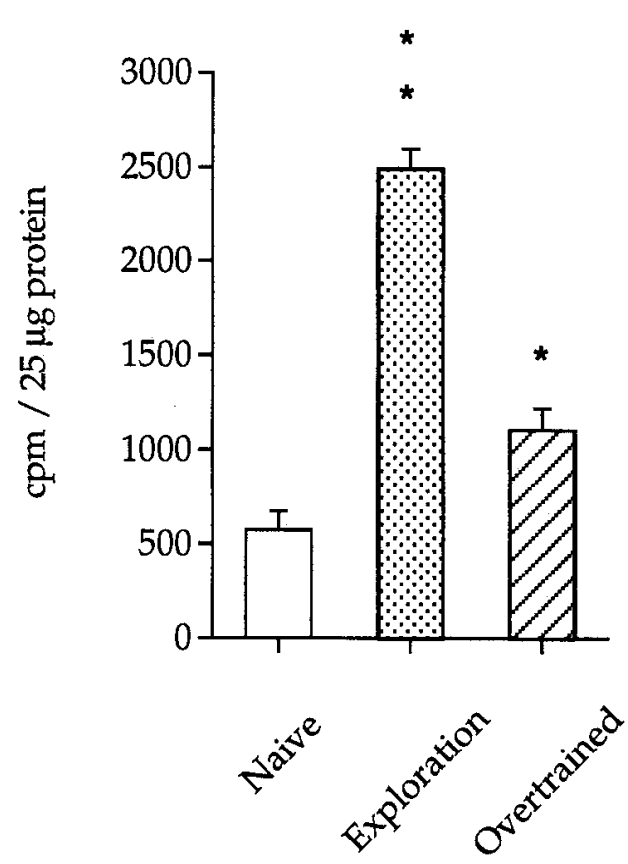

Figure 5. Bar graph showing levels of c-fos cRNA hybridization in piriform cortex for the three animal treatment groups. Bars indicate group mean values $( \pm \mathrm{SE})\left(p<0.0001\right.$ ANOVA; ${ }^{*}, p<0.01 ; * *, p<$ 0.001 Student-Newmann-Keuls).

cell spiking in CA3, are likely to have substantial impact on the number of CA1 neurons that discharge during a behavioral episode. Elevated input from the dentate gyrus could produce either or both types of effects in CA3. In any event, the pattern of c-fos expression observed in the present experiments is of a type that would be expected under conditions in which the full trisynaptic, intrahippocampal circuit (i.e., SG to CA3 to CA1) had been repeatedly activated. It should be noted that the direct projections from the entorhinal and perirhinal cortices to field CA1 (reviewed by Witter et al., 1989, and Amaral and Witter, 1989) may also modulate activity in this hippocampal subfield under certain behavioral conditions.

The distinguishing characteristics of the "common mode" are suggestive of conditions that elicit it and of the type of contributions it may make to brain operations. Concerning the former, stratum granulosum receives its dominant input from the entorhinal cortex (Witter et al., 1986, 1989; Amaral and Witter, 1989), a structure that itself is innervated by sensory systems (Witter et al., 1986, 1989; Insausti et al., 1987; Witter, 1993). The granule cells are also largets of a complex collection of excitatory (associational) and inhibitory neurons located in the hilus (Amaral and Witter, 1989; Ribak and Seress, 1983; Ribak et al., 1985; Halasy and Somogyi, 1993; Han et al., 1993) which receive input from the septum/diagonal bands and the ascending monoaminergic systems (Lynch et al., 1977; Swanson, 1977; Nyakas et al., 1987; Loy and Moore, 1979; Freund et al., 1990; Miettinen and Freund, 1992). This collection of anatomical features encourages the hypothesis that intense activation of (and c-fos induction in) the granule cells may result from repeated sampling of environmental stimuli in association with some pattern of septal/brainstem activation. Circumstances of this type do in fact occur during the performance of a two-odor discrimination by well-trained rats. Recording studies indicate that the animals engage in a stereotyped sniffing pattern when presented with odors and that this behavior synchronizes activity in the 

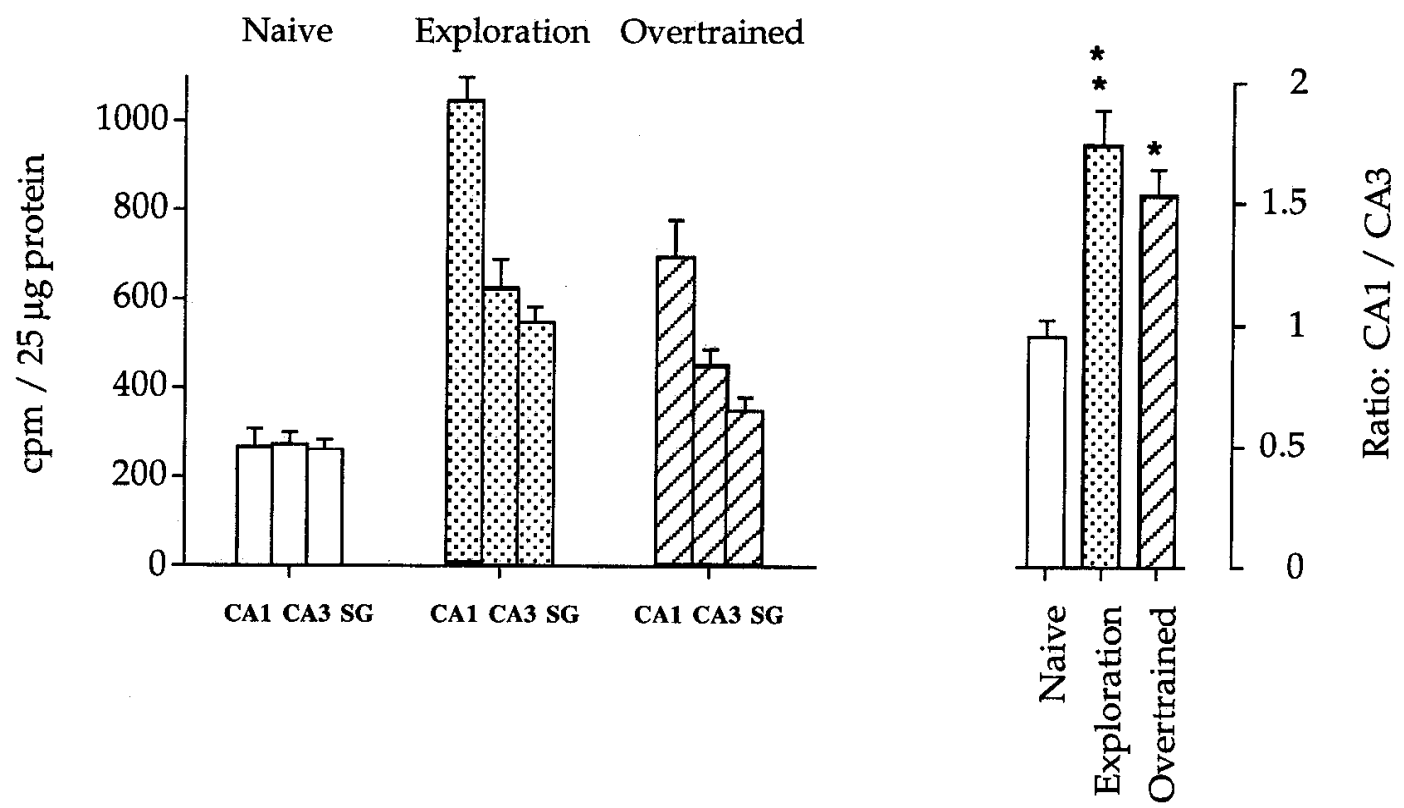

Figure 6. Bar graphs showing $(A)$ densities of hybridization to c-fos mRNA in dorsal hippocampus and $(B)$ ratios of hybridization in CA1/CA3 for the three groups. $A$, Hybridization was significantly increased above control levels in the three hippocampal subdivisions in both exploration and overtrained rats ( $p<0.0001$ ANOVA; $p<0.001$ and $p<0.05$, respectively, Student-Newmann-Keuls), with similar relative levels of expression across subfields evident in the two groups (i.e., CA1 > CA3 $\geq \mathrm{SG}$ ). For statistical comparisons of hybridization levels in stratum granulosum of overtrained versus naive rats, one of the eight naive rats was excluded as an outlier since measures from this rat fell greater than 2 SDs from the group mean. $B, \mathrm{CA} 1: \mathrm{CA} 3$ ratios show that the relative distribution of hybridization across these subfields is similar in the exploration and overtrained groups even though absolute expression levels differed between the treatments ( $p=0.0001$ ANOVA; ${ }^{*}, p<0.01$; ${ }^{*}, p<0.001$ Student-NewmannKculs test for CA1:CA3 ratio comparisons to the naive group).

sequence of connections leading from the olfactory bulb through cortex and into hippocampus (Komisaruk, 1970; Macrides, 1975; Macrides et al., 1982). Such experiments have also shown that cells in field CA1, at least, fire with short latencies and in synchronized bursts in response to odors used as discriminative cues (Eichenbaum et al., 1987; Wiener et al., 1989), indicating that events in olfactory bulb and cortex drive hippocampal circuitry during sampling. The septum plays a prominent role in organizing rhythmic activity in hippocampus (Nicoll, 1985; see Bland, 1986, for review) and hence it can be assumed that the septal projections to the infragranular dentate gyrus make a significant contribution to the synchronization that emerges in performance of a discrimination. Thus, the coordinated temporal convergence of sensory and septal inputs, an event certain to strongly affect granule cell firing, provides a reasonable explanation for the induction of c-fos in these neurons during the performance of an already learned two-odor discrimination.

Exploration also involves sampling of cues that, like odors, are associated with distant objects. Electrophysiological studies have shown that rhythmic activity occurs in hippocampus during cxploration and is accompanied by synchronized bursts of cell spiking in CA1 that are coded to particular spatial cues (Hill, 1978; Muller et al., 1987; Eichenbaum et al., 1989). There are thus reasons to assume that septal (synchronizing) and sensory (spatial) inputs converge repeatedly in the dentate gyrus during exploration. The observations of Buzsaki (1989) that the activity of granule cells is significantly greater during theta-concurrent exploratory activities as opposed to consummatory behaviors are in accord with this idea. In all, then, exploration and perfor- mance of odor discrimination, while very different in most regards, both involve an attentive sampling of distal cues, rhythmic activity, and short latency responses in hippocampus.

The observation that levels of c-fos mRNA in the piriform cortex and dentate gyrus were highly correlated across rats performing a well-learned discrimination but not in the other groups (Table 2) further supports the idea that neuronal activity in the two regions is linked during active sampling of pertinent cues. The piriform is the source of a large projection to the lateral entorhinal cortex which in turn densely innervates the granule cells of the dentate gyrus (Zimmer, 1971; Wyss, 1981; Price, 1987; reviewed by Switzer et al., 1985). This disynaptic circuit provides a means whereby extensive training using odors as discriminative cues results in a coordination betwecn cortical and hippocampal activity. A similar result was not obtained for visual cortex in the exploration animals (Table 2). The links between the visual system and dentate gyrus are likely to be more complex than those for olfactory cortex and indeed may include circuitries in addition to those passing through neocortex (Thompson and Robertson, 1987a,b). It will be of considerable interest in future studies to determine if $\mathrm{c}-$ fos expression in other forebrain regions related to vision correlate with activities in dentate gyrus during exploration; areas that exhibit such an effect would be candidates for the relays that communicate spatial information to hippocampus, an issue that is of some importance in its own right.

The pattern of c-fos expression associated with exploration and odor discrimination was also characterized by differential labeling of the two output segments of hippocampal circuitry, 

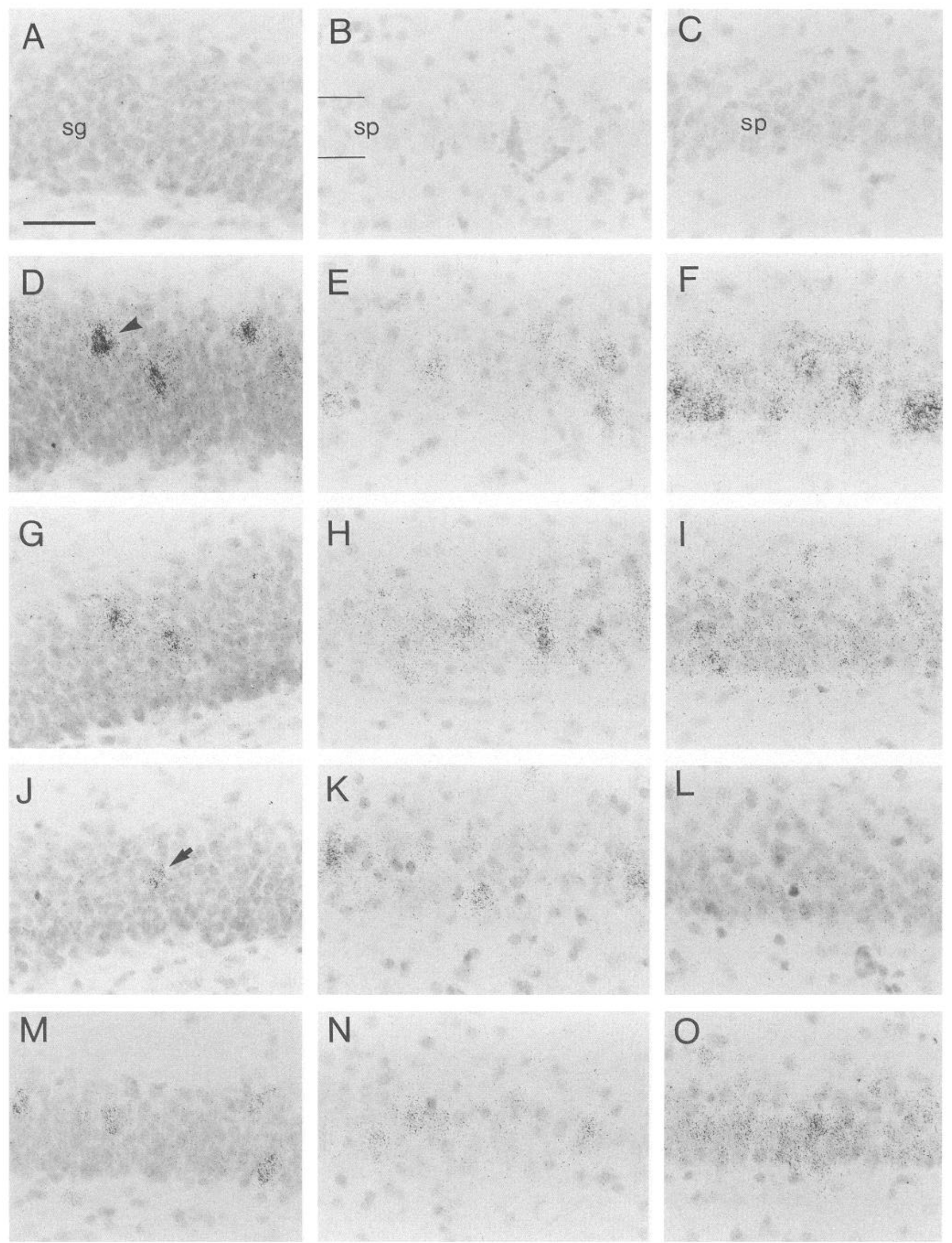

Figure 7. High magnification photomicrographs showing the autoradiographic localization of hybridization within stratum granulosum ( $s g$ ) (left column), CA3 stratum pyramidale ( $s p$ ) (middle column), and CA1 stratum pyramidale ( $s p$ ) (right column) for the various groups: $A-C$, home cage 
that is, field CA1 had substantially higher levels of mRNA than did field CA3. The CA1 region, via connections with subiculum and retrohippocampal cortex, as well as through direct projections, densely innervates the ventral striatum (nucleus accumbens) and anterior olfactory nucleus (Van Groen and Wyss, 1990; Brog et al., 1993). The ventral striatum appears to organize locomotor activities of a general type (Evarts et al., 1984; Koob et al., 1991; Mogenson and Yang, 1991; Salamone, 1992) and has been suggested to play a role in exploratory behavior (Mogenson and Nielson, 1984; Schacter et al., 1989). The anterior olfactory nucleus is a large structure that sends its axons to the granule cell layer of the ipsilateral and contralateral olfactory bulb (reviewed by Switzer et al., 1985) and thus constitutes a major contributor to the regulation of bulbar output to cortex. These observations suggest the hypothesis that the hippocampal pattern of c-fos expression obtained with the behaviors used in the present studies reflects an operation whereby the three subdivisions link sampled distant cues to (1) cellular machinery that organizes movement through space and (2) the flow of olfactory information into forebrain networks.

Higher resolution analysis of tissue autoradiograms indicated that hippocampal c-fos expression was detectably different in the exploration versus performance groups at the cellular level. These differences corresponded with quantitative regional differences indicating greater levels of c-fos mRNA in CA1 and dentate gyrus of exploration rats. In stratum granulosum, labeled neurons occurred in pairs or small clusters in both behavioral situations, but hybridization to individual cells appeared to be more intense in exploration animals. Exploration animals also had clusters of labeled cells in field CA1, a pattern that was casily distinguished from the more diffuse hybridization seen in the overtrained group. These differences might be due to increased levels of arousal in rats placed in a novel environment; it is noteworthy in this regard that the diffuse noradrenergic projections from the locus coeruleus are proposed to increase levels of neuronal activity in the forebrain (Loughlin et al., 1986). It is also conceivable that the differences are related to one of the more prominent behavioral distinctions between the two groups, namely, that exploration involves encoding while performance makes use of already learned information. A considerable body of evidence has implicated long-term potentiation (LTP) as a substrate for several varieties of memory (see Lynch et al., 1991; Lynch and Granger, 1992, for reviews) and it is known that induction of LTP requires depolarization of a degree and duration greater than that needed to trigger action potentials (Bliss and Collingridge, 1993). Possibly, the denser hybridization seen in single neurons in the exploration groups is due to the occurrence of postsynaptic responses of a type required for the development of LTP. With regard to this idea, it would be interesting to compare labeling in well-trained rats that have recently acquired a novel odor discrimination with that obtained in animals tested with a well-learned discrimination.

The occurrence of the above noted small neuronal clusters in
Table 1. Relative levels of c-fos mRNA in three hippocampal subdivisions during various stages of the odor discrimination paradigm

\begin{tabular}{llll} 
& SG & CA3 & CA1 \\
\hline $\begin{array}{l}\text { 1. Exploration of novel apparatus } \\
\text { 2. Learn nose poke response }\end{array}$ & 2 & 2 & 4 \\
$\begin{array}{l}\text { 3. Perform nosc pokc responsc } \\
\text { 4. Acquire two-odor discrimination }\end{array}$ & $\varnothing$ & 2 & 2 \\
$\begin{array}{l}\text { 5. Perform known discriminations } \\
\text { ("Overtrained") }\end{array}$ & 1.5 & 2 & 3 \\
$\begin{array}{l}\text { 6. Rapid acquisition of novel } \\
\text { discriminations }\end{array}$ & & & \\
\end{tabular}

SG, stratum granulosum. $\varnothing=$ control levels; $1=$ significantly increased above control by $\sim 16 \% ; 1.5=-33 \%$ greater than control; $2=194 \pm 24 \%$ (mean $\pm \mathrm{SD})$ greater than control; $3=\sim 260 \%$ greater than control; $4=\sim 390 \%$ greater than control. In step 4 , the $\mathrm{CA} 3 / \mathrm{CA} 1$ ratio is $1.82 \pm 0.18$. In step 5 , the $\mathrm{CA} 1 / \mathrm{CA} 3$ ratio is $1.53 \pm 0.11$, and the $\mathrm{CA} 1 / \mathrm{SG}$ ratio is $1.99 \pm 0.06$.

the dentate gyrus indicates that a subpopulation of cells was activated repeatedly during behavior and that these cells tended to be neighbors. Repeated activation probably reflects the presence of a limited number of salient cues in the environment. The proximity effect is not unexpected assuming (1) that activation requires convergence of active afferents and (2) some degree of intermingling of dendritic trees (Barnes et al., 1987). It might be noted that the spatial granularity of hybridization, as seen in tissue autoradiograms, is in accord with the general hypothesis that c-fos induction during exploration and discrimination is driven by discrete influences (e.g., sampled cues).

\section{c-fos mRNA expression in sensory systems}

Results for the sensory systems are summarized in Table 3 . Note that the exploration animals had generally greater expression in olfactory regions than did other groups, and were unusual in having much higher levels of c-fos mRNA in the granular than in the glomerular layer of the olfactory bulb. The glomerular cells are thought to regulate the initial stages of processing of sensory input from the olfactory nerve (reviewed by Switzer et al., 1985) while neurons in the granular cell layer and piriform cortex are tightly connected with the output (mitral) cells of the bulb (Haberly and Price, 1977; Switzer et al., 1985). It is thus possible that the pattern seen in the exploration rats reflects the continuous sampling of odors exhibited by these animals.

Also of interest is the observation that the bulbar c-fos expression profile evoked during discrimination of familiar odors differed from that observed during initial learning of the same odors. We have previously reported that c-fos mRNA is induced during task acquisition in three distinct glomerular and underlying granule cell fields located laterally at intermediate levels of the bulb (Hess et al., 1995). This topographic response corresponds well with that obtained by controlled exposure to peppermint odor (the "positive," predominantly sampled odor in

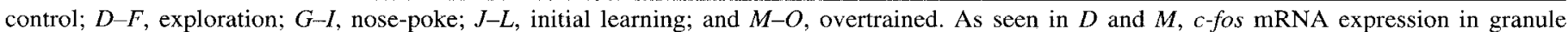

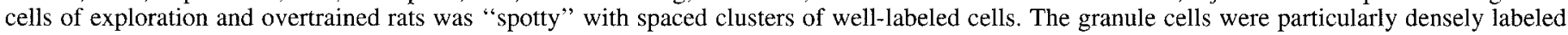

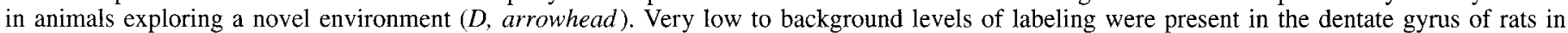

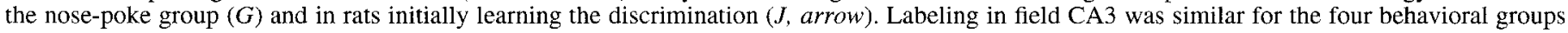

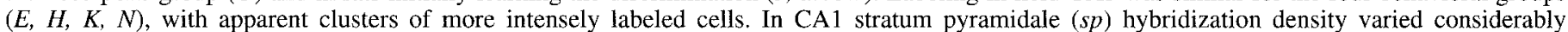

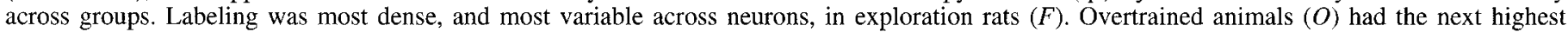

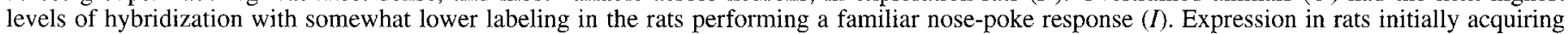
the odor discrimination $(L)$ was only slightly above control levels. Scale bar: $55 \mu \mathrm{m}$. 

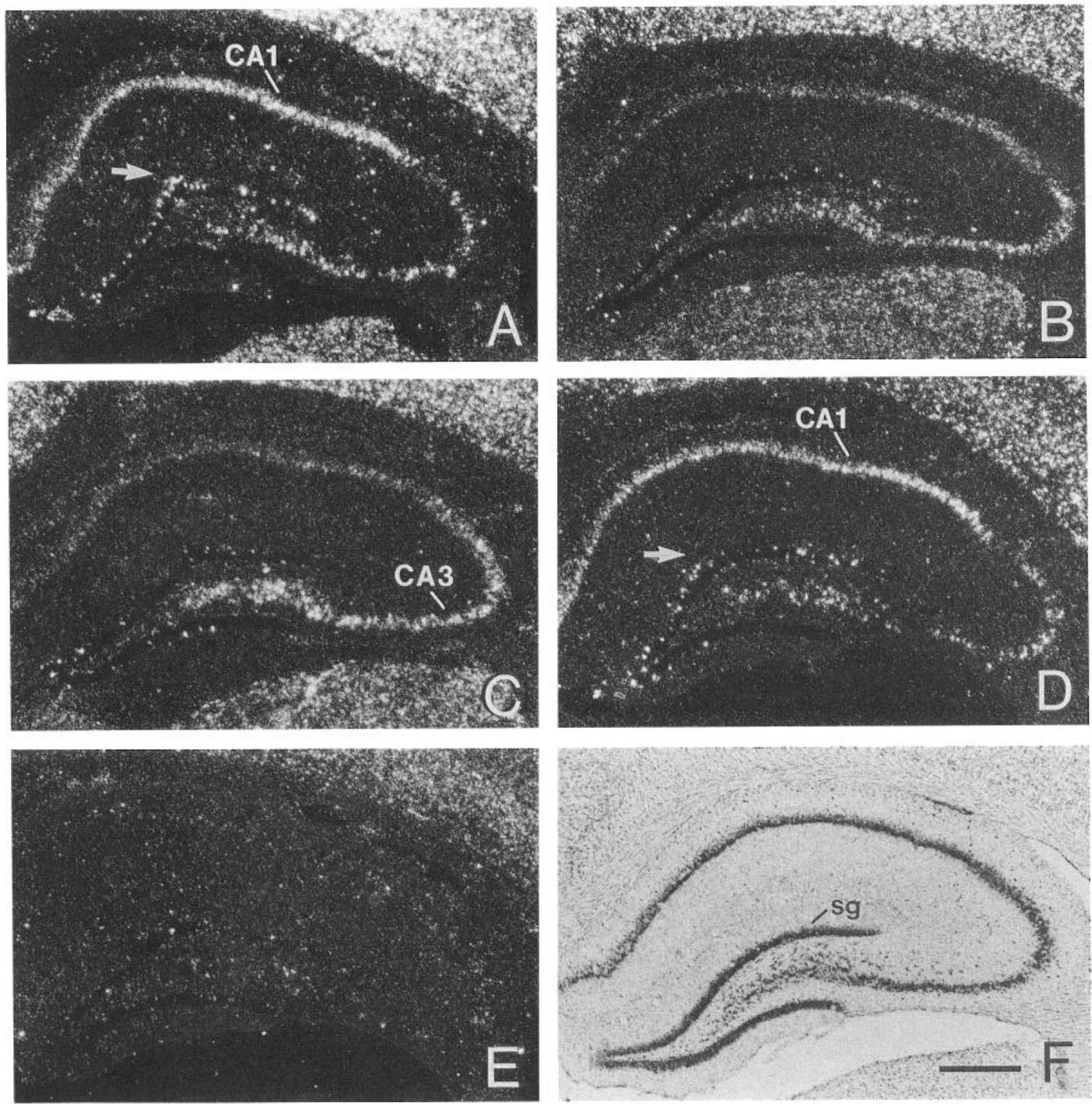

Figure 8. Dark-field photomicrographs of tissue autoradiograms showing differential patterns of c-fos mRNA expression in the hippocampus of animals performing at different stages in the olfactory learning paradigm. Exploration of the novel training apparatus $(A)$ resulted in a pattern of "CA1 dominance" with significantly greater labeling in CA1 than in field CA 3 or the granule cells. Performance of the nose-poke response (B) increased hybridization in CA1b and CA3 with no appreciable difference between them. It was noted that labeling density tended to be lower in the portion of CA1 closest to the subiculum (CA1a) than in CA1b in the nose poke group. However, CA1a was not measured. Acquisition of the discrimination task $(C)$ induced a pattern of "CA3 dominance"; densities of hybridization were notably greater in field CA3 than CA1. Overtrained animals $(D)$ performing on a familiar odor pair exhibited a similar pattern of increased c-fos expression as observed in exploration rats $(A)$ (i.e., "CA1 dominance") but lower absolute hybridization densities. Note that $c$-fos expression in the suprapyramidal stratum granulosum (sg) was induced above basal levels only in the animals exploring the training apparatus ( $A$; see arrow) and in those performing a well-learned odor discrimination $(D$, arrow). Naive rats $(E)$ had uniformly low levels of hybridization across the three hippocampal subfields. A Nissl stained hippocampal section $(F)$ is shown to provide anatomical detail. Scale bar, $500 \mu \mathrm{m}$.

Table 2. Correlation coefficients for c-fos mRNA levels in stratum granulosum versus sensory cortical regions for the various treatment groups

\begin{tabular}{|c|c|c|c|c|c|}
\hline & Naive & Exploration & Nose poke & $\begin{array}{l}\text { Acquisition } \\
\text { of odor } \\
\text { pair }\end{array}$ & Overtrained \\
\hline Piriform cortex vs SG & 0.88 & 0.06 & 0.06 & 0.00 & 0.91 \\
\hline Visual cortex vs SG & 0.90 & 0.40 & 0.32 & 0.23 & 0.44 \\
\hline Piriform vs visual cortex & 0.99 & 0.70 & 0.70 & 0.85 & 0.44 \\
\hline
\end{tabular}

Values represent correlation coefficients $(r)$. SG, Stratum granulosum. 
Table 3. c-fos mRNA expression in olfactory and visual regions in four of several stages of the olfactory discrimination paradigm

\begin{tabular}{|c|c|c|c|c|c|c|}
\hline & \multicolumn{2}{|c|}{ Olfactory bulb } & \multirow{2}{*}{$\begin{array}{l}\text { Piriform } \\
\text { cortex }\end{array}$} & \multicolumn{2}{|c|}{ Superior colliculus } & \multirow{2}{*}{$\begin{array}{l}\text { Occipital } \\
\text { cortex, } \\
\text { superficial }\end{array}$} \\
\hline & Medial GL & Lateral GL & & Medial & Lateral & \\
\hline Exploration & $1591 \pm 100$ & $1243 \pm 72$ & $2495 \pm 102$ & $820 \pm 79$ & $548 \pm 38$ & $1922 \pm 126$ \\
\hline Perform nose poke & $1236 \pm 86$ & $1044 \pm 107$ & $1358 \pm 154$ & $1653 \pm 155$ & $730 \pm 80$ & $1379 \pm 53$ \\
\hline Acquire discrimination & $866 \pm 57$ & $1007 \pm 58$ & $1039 \pm 166$ & $1166 \pm 158$ & $653 \perp 55$ & $806 \perp 92$ \\
\hline Overtrained on discrimination & $1209 \pm 69$ & $1374 \pm 63$ & $1099 \pm 117$ & $1722 \pm 174$ & $705 \pm 82$ & $1206 \pm 103$ \\
\hline
\end{tabular}

Values represent means $\pm \mathrm{SE}$ and are in $\mathrm{cpm} / 25 \mu \mathrm{g}$ protein. GL, Glomerular layer.

the discrimination paradigm) (Guthrie et al., 1993). In overtrained rats, there were no significant differences in expression between medial and Iateral aspects of the olfactory bulb, although there was a trend for more labeling in the lateral versus the medial glomerular layer. Thus, it appears that novel and welllearned odors elicit different responses even at primary stages of sensory processing. This may be accounted for by ACh, NE, and/or 5-HT centrifugal projections (see Macrides and Davis, 1983, for review; Zaborszky et al., 1986; McLean and Shipley, 1987; Zheng et al., 1987; Gervais et al., 1988; McLean et al., 1989; Le Jeune and Jourdan, 1993) differentially shaping and enhancing bulbar response patterns across bchavioral situations.

The exploration group had very high levels of c-fos mRNA in the visual cortex but not in the superior colliculus; indeed, the exploration animals had lower levels of c-fos mRNA in medial superior colliculus than the other groups. This suggests that arousal and stress, which are presumably high in animals placed in a novel environment, have greater effects on cortex than on lower brain regions. That each of the remaining groups had strong responses in the medial colliculus may relate to the nose poking responses they used to obtain rewards.

Animals overtrained on the two-odor discrimination were quite similar to the nose-poke group with regard to levels and patterns of expression in the visual system. They were unusual, however, in that levels of c-fos mRNA in piriform cortex were low relative to those in olfactory bulb or visual cortex. Chronic recording studies have shown that a very small percentage of the neurons in olfactory cortex respond to odors in the two-odor discrimination paradigm (McCollum et al., 1991). Moreover, only a few samples (i.e., high-frequency sniffs) may be required by well-trained rats to make a correct choice (Coopersmith and Leon, 1984; Coopersmith et al., 1986). This amount of sampling apparently does not cause aggregate activity to be increased above the levels seen in alert rats not engaged in odor directed bchaviors. Howcver, expression in the piriform cortex did not correlate with that in visual cortex for rats in the overtrained group but did for the other groups (Table 2). This suggests that individual variations in performance of the discrimination were sufficient to obscure the generalized effects of arousal, and other state variables, on the piriform cortex. It will be of considerable interest to determine if hybridization as seen at the level of single cells is in some way different in the overtrained discrimination animals than in the other groups.

In summary, absolute and relative levels of c-fos mRNA across olfactory and visual structures are not in any obvious way predictive of observed variations in hippocampal patterns of expression. Studies are now in progress to identify structures that exhibit high levels of expression in the exploration and overtrained animals but not in the two other groups thus far analysed. Information of this kind would likely be of considerable value in developing explanations of how disparate behaviors elicit a common hippocampal response. It will also be of interest in future studies to determine whether the pattern of expression of other immediate early genes (e.g., zif/268 and tissue-plasminogen activator) (Qian et al., 1993; Worley et al., 1993) is comparable in behavioral conditions evoking a similar c-fos mRNA response.

\section{References}

Amaral DG, Witter MP (1989) The three-dimensional organization of the hippocampal formation: a review of anatomical data. Neuroscience 31:571-591.

Barnes CA, Rao G, McNaughton BL (1987) Increased electrotonic coupling in aged rat hippocampus: a possible mechanism for cellular excitability changes. J Comp Neurol 259:549-558.

Bland BH (1986) The physiology and pharmacology of hippocampal formation theta rhythms. Prog Neurobiol 26:1-54.

Bliss TV, Collingridge GL (1993) A synaptic model of memory: longterm potentiation in the hippocampus. Nature 361:31-39.

Brog JS, Salyapongse A, Deutch AY, Zahm DS (1993) The patterns of afferent innervation of the core and shell in the "accumbens" part of the rat ventral striatum: immunohistochemical detection of retrogradely transported fluoro-gold. J Comp Neurol 338:255-278.

Buzsaki G (1989) Two-stage model of memory trace formation: a role for "noisy" brain states. Neuroscience 31:551-570.

Coopersmith R, Leon M (1984) Enhanced neural response to familiar olfactory cues. Science 225:849-851.

Coopersmith R, Henderson SR, Leon M (1986) Odor specificity of the enhanced neural response following early odor experience in rats. Dev Brair Res 27:191-197.

Curran T, Gordon MB, Rubino KL, Sambucetti LC (1987) Isolation and characterization of the c-fos (rat) cDNA and analysis of posttranslational modification in vitro. Oncogene 2:79-84.

Dragunow M, Faull R (1989) The use of c-fos as a metabolic marker in neuronal pathway tracing. J Neurosci Methods 29:261-265.

Ehret G, Fischer R (1991) Neuronal activity and tonotopy in the auditory system visualized by c-fos gene expression. Brain Res 567 : 350-354.

Eichenbaum H, Kuperstein M, Fagan A, Nagode J (1987) Cue-sampling and goal-approach correlates of hippocampal unit activity in rats performing an odor-discrimination task. J Neurosci 7:716-732.

Eichenbaum H, Wiener SI, Shapiro ML, Cohen NJ (1989) The organization of spatial coding in the hippocampus: a study of neural ensemble activity. J Neurosci 9:2764-2775.

Evarts EV, Kimura M, Wurtz RH, Hikosaka O (1984) Behavioral correlates of activity in basal ganglia neurons. Trends Neurosei 7:447453.

Freund TF, Gulyas AI, Acsady L, Gorcs T, Toth K (1990) Serotonergic control of the hippocampus via local inhibitory interncurons. Proc Natl Acad Sci USA 87:8501-8505.

Gall C, Murray K, Isackson PJ (1991) Kainic acid-induced seizures stimulate increased expression of nerve growth factor mRNA in rat hippocampus. Mol Brain Res 9:113-123.

Gall CM, Berschauer R, Isackson PJ (1994) Seizures increase basic tibroblast growth factor mRNA in adult rat forebrain neurons and glia. Mol Brain Res 21:190-205.

Gervais R, Holley A, Keverne B (1988) The importance of central noradrenergic influences on the olfactory bulb in the processing of learned olfactory cues. Chem Senses 13:3-12. 
Greenberg ME, Ziff EB, Greene LA (1986) Stimulation of neuronal acetylcholine receptors induces rapid gene transcription. Science 234: 80-83.

Guthrie KM, Anderson AJ, Leon M, Gall C (1993) Odor-induced increases in c-fos mRNA expression reveal an anatomical "unit" for odor processing in olfactory bulb. Proc Natl Acad Sci USA 90:3329_ 3333.

Haberly LB, Price JH (1977) The axonal projection patterns of the mitral and tufted cells of the olfactory bulb in the rat. Brain Res 129: 152-157.

Halasy K, Somogyi P (1993) Subdivisions in the multiple GABAergic innervation of granule cells in the dentate gyrus of the rat hippocampus. Eur J Neurosci 5:411-429.

Han ZS, Buhl EH, Lorinczi Z, Somogyi P (1993) A high degree of spatial selectivity in the axonal and dendritic domains of physiologically identified local-circuit neurons in the dentate gyrus of the rat hippocampus. Eur J Neurosci 5:395-410.

Hess US, Lynch G, Gall CM (1995) Changes in c-fos mRNA expression in rat brain during odor discrimination learning: differential involvement of hippocampal subfields $\mathrm{CA} 1$ and $\mathrm{CA} 3$. J Neurosci 15:4786-4795.

Hill AJ (1978) First occurrence of hippocampal spatial firing in a new environment. Exp Neurol 62:282-297.

Hunt SP, Pini A, Evan G (1987) Induction of c-fos-like protein in spinal cord neurons following sensory stimulation. Nature 328:632-634.

Insausti R, Amaral DG, Cowan WM (1987) The entorhinal cortex of the monkey. II. Cortical afferents. J Comp Neurol 264:356-395.

Irwin KB, Craig AD, Bracha V, Bloedel JR (1992) Distribution of c-fos expression in brainstem neurons associated with conditioning and pseudo-conditioning of the rabbit nictitating membrane reflex. Neurosci Lett 148:71-75.

Jay TM, Witter MP (1991) Distribution of hippocampal CA1 and subicular efferents in the prefrontal cortex of the rat studied by means of anterograde transport of Phaseolus vulgaris-leucoagglutinin. J Comp Neurol 313:574-586.

Komisaruk BR (1970) Synchrony between limbic system theta activity and rhythmical behavior in rats. $J$ Comp Physiol Psychol 70:482492.

Koob GF, Swerdlow NR, Vaccarino F, Hubner C, Pulvirenti L, Weiss F (1991) Functional output of the basal forebrain. Adv Exp Med Biol 295:291-305.

Lauterborn JC, Isackson PJ, Montalvo R, Gall CM (1993) In situ hybridization localization of choline acetyltransferase mRNA in adult rat brain and spinal cord. Mol Brain Res 17:59-69.

Le Jeune H, Jourdan F (1993) Cholinergic innervation of olfactory glomeruli in the rat: an ultrastructural immunocytochemical study. J Comp Neurol 336:279-292.

Loughlin SE, Foote SL, Bloom FE (1986) Efferent projections of nucleus locus coeruleus: topographic organization of cells of origin demonstrated by three-dimensional reconstruction. Neuroscience 18: 291-306.

Loy R, Moore RY (1979) Ontogeny of the noradrenergic innervation of the rat hippocampal formation. Anat Embryol 157:243-253.

Lynch G, Granger R (1992) Variations in synaptic plasticity and types of memory in cortico-hippocampal networks. J Cognit Neurosci $4: 189-199$.

Lynch G, Larson J, Staubli U, Granger R (1991) Variants of synaptic potentiation and different types of memory operations in hippocampus and related structures. In: Memory: organization and locus of change (Squire LR, Weinberger NM, Lynch G, McGaugh JL, ed), pp 339-363. New York: Oxford UP.

Lynch G, Rose G, Gall C (1977) Anatomical and functional aspects of the septo-hippocampal projections. CIBA Found Symp 58:5-24.

Macrides F (1975) Temporal relationships between hippocampal slow waves and exploratory sniffing in hamsters. Behav Biol 14:295-308.

Macrides F, Davis BJ (1983) The olfactory bulb. In: Chemical neuroanatomy (Emson PC, ed), pp 391-426. New York: Raven.

Macrides F, Eichenbaum HB, Forbes WB (1982) Temporal relationship between sniffing and the limbic theta rhythm during odor discrimination reversal learning. J Neurosci 2:1705-1717.

McCollum J, Larson J, Otto T, Schottler F, Granger R, Lynch G (1991) Short-latency single-unit processing in olfactory cortex. J Cognit Neurosci 3:293-299.

McLean JH, Shipley MT (1987) Serotonergic afferents to the rat ol- factory bulb. I. Origins and laminar specificity of serotonergic inputs in the adult rat. J Neurosci 7:3016-3028.

McLean JH, Shipley MT, Nickell WT, Aston-Jones G, Reyher CKH (1989) Chemoanatomical organization of the noradrencrgic input from locus coeruleus to the olfactory bulb of the adult rat. J Comp Neurol 285:339-349.

Miettinen R, Freund TF (1992) Convergence and segregation of septal and median raphe inputs onto different subsets of hippocampal inhibitory interneurons. Brain Res 594:263-272.

Mogenson GJ, Nielson M (1984) Neurochemical evidence to suggest that the nucleus accumbens and subpallidal regions contribute to exploratory locomotion. Behav Neural Biol 42:52-60.

Mogenson GJ, Yang CR (1991) The contribution of basal forebrain to limbic-motor integration and the mediation of motivation to action. Adv Exp Med Biol 295:267-290.

Morgan JI, Curran T (1986) Role of ion flux in the control of c-fos expression. Nature 322:552-555.

Morgan JI, Curran T (1991) Stimulus-transcription coupling in the nervous system: involvement of the inducible proto-oncogenes fos and jun. Annu Rev Neurosci 14:421-451.

Morgan JI, Cohen DR, Hempstead JL, Curran T (1987) Mapping patterns of c-fos expression in the central nervous system after seizure. Science 237:192-197.

Muller RU, Kubie JL, Ranck JBJ (1987) Spatial firing patterns of hippocampal complex-spike cells in a fixed environment. $J$ Neurosci 7:1935-1950.

Nicoll RA (1985) The septo-hippocampal projection: a model cholinergic pathway. Trends Neurosci 12:533-536.

Nikolaev E, Kaminska B, Tischmeyer W, Matthies H, Kaczmarck L (1992) Induction of expression of genes encoding transcription factors in the rat brain elicited by behavioral training. Brain Res Bull $28: 479-484$

Nyakas C, Luiten PGM, Spencer DG, Traber J (1987) Detailed projection patterns of septal and diagonal band efferents to the hippocampus in the rat with emphasis on innervation of $\mathrm{CA} 1$ and dentate gyrus. Brain Res Bull 18:533-545.

Paxinos G, Watson C (1986) The rat brain in stereotaxic coordinates. San Diego, CA: Academic.

Price JL (1987) The central olfactory and accessory olfactory systems. In: The neurobiology of taste and smell (Finger TE, Silver WL, ed), pp 205. New York: Wiley.

Qian Z, Gilbert ME, Colicos MA, Kandel ER, Kuhl D (1993) Tissueplasminogen activator is induced as an immediate-early gene during seizure, kindling and long-term potentiation. Nature 361:453-457.

Ribak CE, Seress L (1983) Five types of basket cell in the hippocampal dentate gyrus: a combined Golgi and electron microscopic study. J Neurocytol 12:577-597.

Ribak CE, Seress L, Amaral DG (1985) The development, ultrastructure and synaptic connections of the mossy cells of the dentate gyrus. J Neurocytol 14:835-857.

Sagar SM, Sharp FR, Curran T (1988) Expression of c-fos protein in brain: metabolic mapping at the cellular level. Science 240:13281331

Salamone JD (1992) Complex motor and sensorimotor functions of striatal and accumbens dopamine: involvement in instrumental be havior processes. Psychopharmacology 107:160-174.

Schacter GB, Yang CR, Innis NK, Mogenson GJ (1989) The role of the hippocampal-nucleus accumbens pathway in radial-arm maze performance. Brain Res 494:339-349.

Sharp FR, Gonzalez MF, Sharp JW, Sagar SM (1989) c-fos expression and $\left({ }^{14} \mathrm{C}\right)$ 2-deoxyglucose uptake in the caudal cerebellum of the rat during motor/sensory cortex stimulation. J Comp Neurol 284:621636.

Shin C, McNamara JO, Morgan JI, Curran T, Cohen DR (1990) Induction of c-fos mRNA expression by afterdischarge in the hippocampus of naive and kindled rats. J Neurochem 55:1050-1055.

Swanson LW (1977) The anatomical organization of septo-hippocampal projections. CIBA Found Symp 58:25-48.

Swanson LW, Cowan WM (1977) An autoradiographic study of the organization of the efferent connections of the hippocampal formation in the rat. J Comp Neurol 172:49-84.

Switzer RC, De Olmos J, Heimer L (1985) Olfactory system. In: The rat nervous system: forebrain and midbrain (Paxinos G, ed), pp 136. Orlando, FL: Academic.

Thompson SM, Robertson RT (1987a) Organization of subcortical 
pathways for sensory projections to the limbic cortex. I. Subcortical projections to the medial limbic cortex in the rat. J Comp Neurol 265:175-188.

Thompson SM, Robertson RT (1987b) Organization of subcortical pathways for sensory projections to the limbic cortex. II. Afferent projections to the thalamic lateral dorsal nucleus in the rat. J Comp Neurol 265:189-202.

Van Groen T, Wyss JM (1990) Extrinsic projections from area CA1 of the rat hippocampus: olfactory, cortical, subcortical, and bilateral hippocampal formation projections. J Comp Neurol 302:515-528.

Wiener SI, Paul CA, Eichenbaum H (1989) Spatial and behavioral correlates of hippocampal neuronal activity. J Neurosci 9:2737-2763.

Witter MP (1993) Organization of the entorhinal-hippocampal system: a review of current anatomical data. Hippocampus 3:33-44.

Witter MP, Groenewegen HJ, Lopes Da Silva FH, Lohman AHM (1989) Functional organization of the extrinsic and intrinsic circuitry of the parahippocampal region. Prog Neurobiol 33:161-253.

Witter MP, Room P. Groenewegen HJ, Lohman AHM (1986) Connections of the parahippocampal cortex in the cat. V. Intrinsic connec- tions; comments on input/output connections with the hippocampus. J Comp Neurol 252:78-94.

Worley PF, Bhat RV, Baraban JM, Erickson CA, McNaughton BL, Barnes CA (1993) Thresholds for synaptic activation of transcrintion factors in hippocampus: correlation with long-term enhancement. J Neurosci 13:4776-4786.

Wyss JM (1981) Autoradiographic study of the efferent connections of entorhinal cortex in the rat. J Comp Neurol 199:495-512.

Zaborszky L, Carlsen J, Brashear HR, Heimer L (1986) Cholinergic and GABAergic afferents to the olfactor y bulb in the rat with special emphasis on the projection neurons in the nucleus of the horizontal limb of the diagonal band. J Comp Neurol 243:488-509.

Zheng LM, Ravel N, Jourdan F (198\%) 'lopography of centrifugal acetylcholinesterase-positive fibres in the olfactory bulb of the rat: evidence for original projections in atypical glomeruli. Neurosci 23: 1083-1093.

Zimmer J (1971) Ipsilateral afferents to the commissural zone of the fascia dentata demonstrated in decommissurated rats by silver impregnation. J Comp Neurol 23:393-416. 